\title{
As curvas do futuro
}

\section{Paulo Eduardo Carvalho}

\author{
Isabel Alves Costa, Rivoli: 1989-2006. Prefácio \\ de Miguel Lobo Antunes e Posfácio de Miguel \\ Honrado. Porto, Edições Afrontamento, 2008, \\ $376 \mathrm{pp}$.
}

Espero ainda, com este trabalho, tentar impedir que nos façam esquecer o sentido que o sentido tem.

Isabel Alves Costa

Num registo que combina factos, muitos factos - e esta é, como sugere Miguel Honrado, uma "longa narrativa, por vezes obsessivamente minuciosa" (345) - com passos extraídos sobretudo da imprensa e pequenos apontamentos de natureza mais pessoal e intimista, Isabel Alves Costa tenta traçar em Rivoli: 1989-2006 o "rasto daquilo que foram treze anos à frente do [Rivoli] Teatro [Municipal], na qualidade de directora artística" (11). Optando por um percurso cronológico, a autora distribuiu o relato na primeira pessoa desta aventura por dezassete capítulos, a que acrescenta ainda um anexo sobre episódios relacionados com a "Venda", Privatização, "Rivolição" e Liquidação daquele equipamento após 2006, e algumas fotografias - sempre poucas face ao tanto que se fez capazes de evocar a diversificada actividade daquele Teatro.

Esta espécie de biografia inicia-se com a aquisição do Teatro em 1988, durante o mandato de Fernando Cabral como Presidente da Câmara Municipal do Porto (CMP), o breve período do Maestro Manuel Ivo Cruz na direcção do então ainda Teatro Rivoli, e a chegada à CMP de Fernando Gomes, em 1990, quando finalmente "a Cultura foi encarada como um desígnio fundamental para o desenvolvimento da Cidade e o Teatro Rivoli como um equipamento fundamental dessa mesma política" (37). Já com Manuela Melo como responsável pelo pelouro da Cultura, é nomeado um Conselho Consultivo, que já integra Isabel Alves Costa, com a intenção de transformar um "teatro degradado, desconfortável, sem equipamento cénico, sem serviços essenciais, sem pessoal qualificado", num "factor de dinamização do quotidiano cultural portuense". Lançado o concurso para a realização do projecto de recuperação do Rivoli, que acabará por ser assegurado pelo arquitecto Pedro Ramalho - e Isabel Alves Costa recorda que as obras foram apoiadas a $75 \%$ pelo FEDER no âmbito do PRONORTE (Programa Operacional do Norte) -, seguem-se os anos dedicados a "pensar o futuro", isto é, a definir o projecto cultural para o Teatro.

Fazendo jus ao seu propósito de recuperar uma "história de afectos", aquilo a que chama "o desejo de um 'nós'", Isabel Alves Costa recorda o processo de constituição das equipas - com destaque para Ana Cristina Vicente, que se manterá no Teatro também até 2006, e Paula

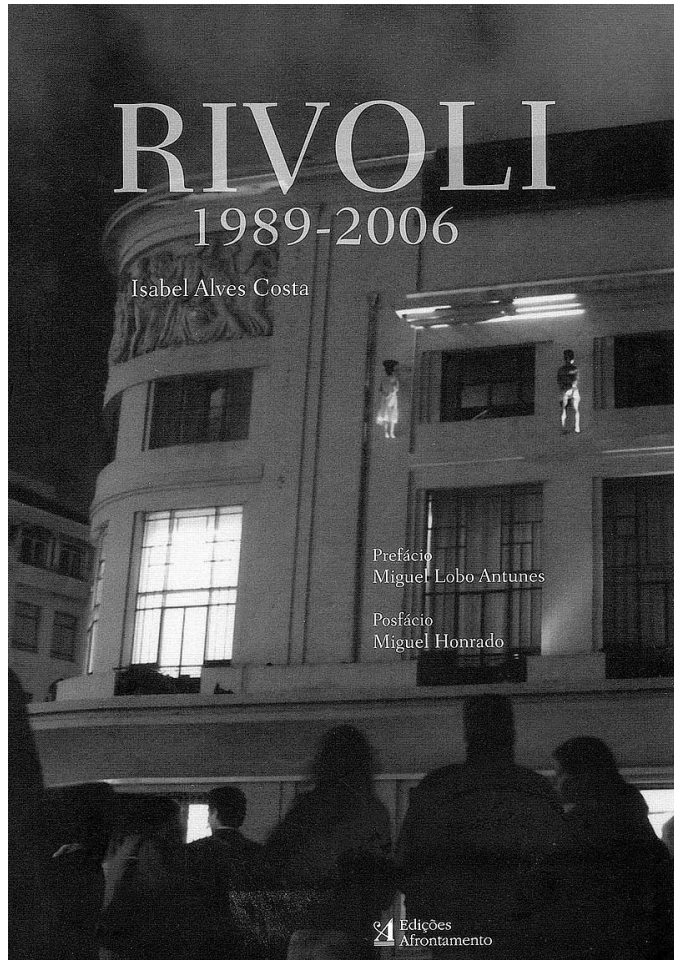

Magalhães, só até 1999 -, a divisão de tarefas por áreas de programação e o empenho participado na tentativa de criação daquilo que então definia também como um

"Teatro do Exercício". A autora refere algumas das iniciativas desenvolvidas, tais como as conversas ao fim da tarde (o "Chá das Seis"), o estabelecimento dos primeiros contactos internacionais, a constituição da Culturporto (associação simultaneamente responsável pela gestão do Rivoli e pela "animação" da cidade), e as trocas de impressões com outros agentes culturais então activos na cidade (como Ricardo Pais ou Fernando Mora Ramos), até à definição de uma filosofia de programação, assente simultaneamente na organização de quadros ou ciclos temáticos e na distribuição por áreas: tomando a "expressão contemporânea da arte" como opção preponderante da programação do Rivoli e com as condicionantes resultantes dos espaços e tempos de apresentação e/ou representação clarificam-se as apostas na dança contemporânea, na música, no teatro e no cinema e vídeo. A abertura do "Rivoli Renovado", a 16 de Outubro de 1997, ocorre num contexto de invulgar agitação cultural na cidade, com a actividade do Teatro Nacional S. João e do então Auditório Nacional Carlos Alberto, de Serralves, do Balleteatro Auditório, de novos grupos de teatro, de festivais, de escolas profissionais artísticas, etc., propiciadoras daquilo 


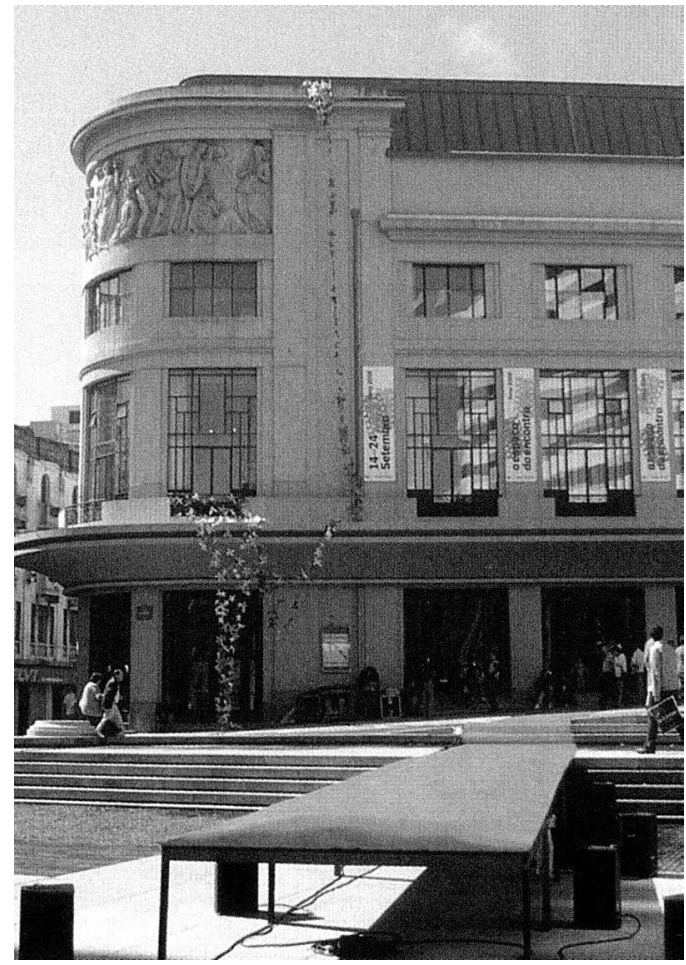

que a autora descreverá mais adiante como a "Rivolimania". Muitos dos capitulos seguintes deste livro listam e recordam os vários artistas e experiências que durante os anos subsequentes foram preenchendo de sentido aquele espaço, assim como as sucessivas lógicas de articulação que foram sendo ensaiadas.

Dos muitos factos coligidos e das observações, mais ou menos pessoais, que vão sendo acrescentadas, ressaltam dimensões importantes, que vão de encontro à percepção que o espectador regular poderia ter do funcionamento daquela casa, cujas principais vocações foram também evoluindo em articulação com as valências de outros agentes locais. Se é indesmentivel a importante função desempenhada pelo Rivoli na co-produção, primeiro, e, mais tarde, no simples acolhimento dos trabalhos das companhias locais que não dispunham de espaço próprio, não é menos inequívoco o investimento numa forte programação nos domínios da dança - e as presenças de Merce Cunningham, Anne Terese de Keersmaeker, William Forsythe e Bill T. Jones durante o ano de 2001 são só a expressão máxima de um dos mais decisivos papéis assumidos pelo Rivoli enquanto serviço público - e, a partir de dada altura, do novo circo. Nos capítulos 8 e 9 , dedicados a uma espécie de balanço dos primeiros três anos e meio de actividade, Isabel Alves Costa aproveita para registar algumas ambições não concretizadas - uma delas prende-se com o Serviço Educativo - e para resumir as primeiras conquistas:

O Rivoli Teatro Municipal, ao fim de três anos e meio de intensa programação, era reconhecido a nivel local, nacional e internacional como um espaço nobre de referência da actividade cultural na cidade do Porto, portador de uma importante missão de serviço público que contribuia para a formação e desenvolvimento cultural dos cidadãos. (...) Com elevados padrões de qualidade, a programação procurou ser criteriosa, sem "cair na tentação" nem do populismo fácil, nem do falso elitismo. (185)

A autora faz acompanhar o registo da euforia programática vivida em 2001 com a consideração retrospectiva de alguma acção "inestruturada", susceptivel de ter contribuido para a diluição da identidade e coesão do próprio Teatro. É também com assumido desassombro que Isabel Alves Costa vai registando, ao longo da sua narrativa, as sucessivas "reestruturações operacionais da Culturporto" promovidas pela CMP, ainda durante a gestão do Partido Socialista, conducentes a uma progressiva, e paradoxal, "subvalorização do trabalho da programação e da Direcção Artística do Rivoli face a todos os outros serviços, nomeadamente os de Produção" (91-2), com um momento particularmente marcante, em finais de Outubro de 2002, quando a Direcção Artística do Teatro deixa de ter assento nos órgãos directivos daquela associação: 'Tendo sido colocada toda a ênfase na 'máquina' Culturporto, o Rivoli 'desaparecia' das fichas técnicas dos programas trimestrais, enquanto departamento e enquanto motor/autor da actividade do Teatro, passando a ser apenas o espaço onde se realizavam todos os espectáculos e programas" (204). Nesta mesma linha - se quisermos, a da história especificamente política de um projecto cultural - se insere o registo das declarações que acompanhariam a chegada de um novo executivo à CMP em 2002 recorde-se $o$ anunciado ataque aos "lóbis culturais da cidade" ou, entre as muitas outras infames declarações de Rui Rio, o "sempre que ouço alguém falar em cultura, puxo da calculadora" - anunciando a estratégia de progressiva asfixia financeira - e os números estão todos no livro - e literal liquidação do Rivoli enquanto prestador de um serviço público, que culminaria na extinção da Culturporto no início de 2007 e na concessão do Teatro a um operador privado.

Por estas e outras razões, este nunca poderia ser um livro comum. Não é comum, entre nós, um tal empenho em recuperar uma história tão recente, particularmente nos domínios da acção cultural. 0 próprio prefaciador, Miguel Lobo Antunes, reconhece: "Não conheço nenhum
Espaço do encontro, Festival Internacional de Marionetas do Porto (FIMP) 2005 a Praça D. João I e a fachada do Rivoli Teatro Municipa 
outro livro igual a este" (16). Tal como não é comum esta

capacidade - esta coragem - de tecer uma história feita de tantas alegrias e tantas outras tristezas. E este é, de facto, um livro tão jubiloso como melancólico, porque ilustra não só o que a imaginação e a competência são capazes de alcançar, mas também a imensa fragilidade $e_{\text {, }}$ neste caso, a confirmada efemeridade dos projectos culturais em Portugal. Uma precariedade que resulta não só dos eventuais efeitos provocados pelas flutuações económicas e financeiras, mas sobretudo da impunidade com que se permite que os nossos decisores políticos continuem a agir, tal é a continuada ausência de consensos alargados e inequivocos sobre aquilo que deveria constituir o nosso destino comum. E por tudo isto, esta também não poderia ser uma recensão comum, pretensamente distanciada e objectiva, justamente porque ela surge motivada por uma ambição que está para lá do livro e da sua específica consideração, servindo-se dela não só para denunciar um dos mais perversos episódios da nossa ainda? - tão deficiente democracia, mas sobretudo para, em sentido completamente contrário, homenagear um desígnio e uma aventura que, para sempre, fará parte da nossa história comum.

A Isabel Alves Costa fez, felizmente, muitas e variadas coisas na sua vida, entre as experiências mais directas de criação e as responsabilidades dedicadas ao estudo, ao ensino ou à programação e propiciação dessa criação. Para além das suas publicações - O desejo do teatro (2003), 0 desejo do teatro: 0 instinto teatral como dado antropológico (2003), Lutar para dar um sentido à vida e O fantoche que ajuda a crescer (com Filipa Baganha, 1989), Perspectivas psicopedagógicas de expressão dramática nos jardins-de-infância (com Maria Alice Guimarães, 1986), A viagem (1983), e ainda os Cadernos do Rivoli que organizou ou promoveu -, criou e dirigiu o Festival Internacional de Marionetas do Porto (FIMP) a partir de 1989, foi responsável pelo Departamento de Artes do Palco da Porto 2001 - Capital Europeia da Cultura, exerceu actividade docente no curso de Estudos Artísticos da
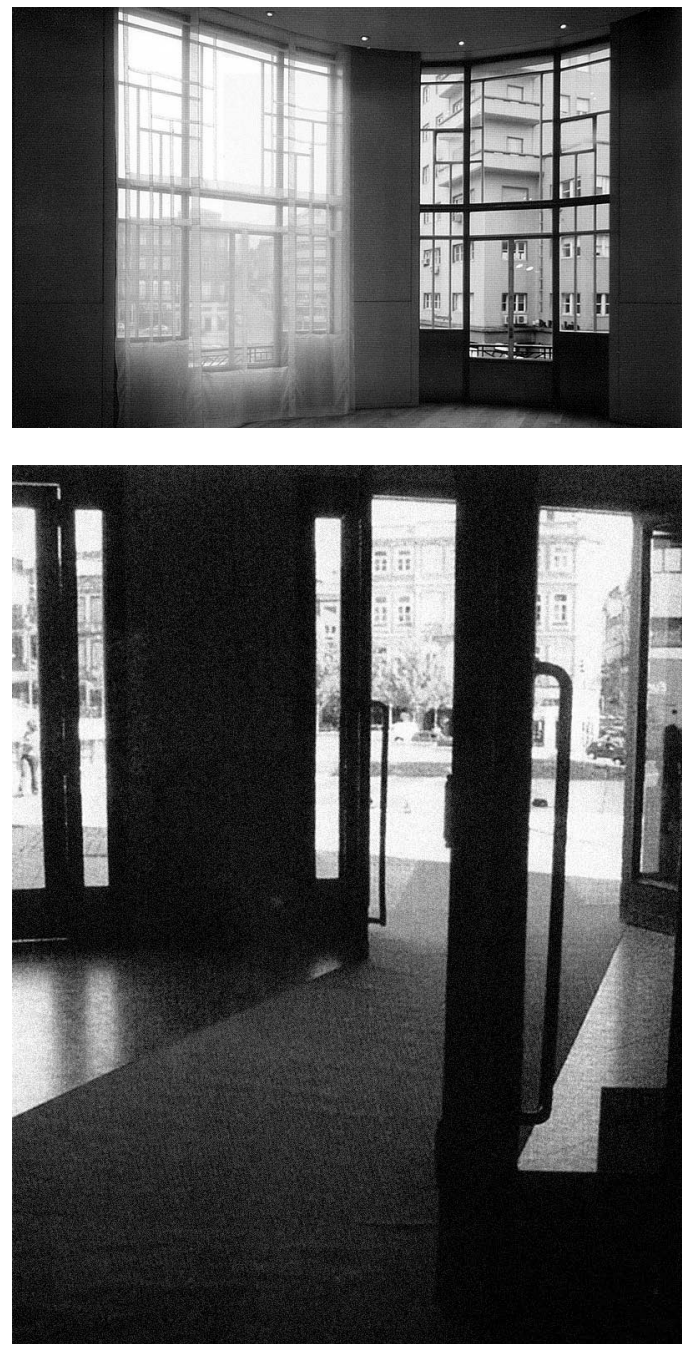

Faculdade de Letras da Universidade de Coimbra e integrou, com empenhada paixão, a Direcção Artística da Associação Comédias do Minho, com sede em Paredes de Coura. Este fazer e esta curiosidade recordam a afirmação quase desesperada de Era preciso fazer as coisas, o título do comovente documentário realizado por Margarida Cardoso em torno da criação de Tio Vânia, encenado por Nuno Carinhas e apresentado no Teatro Carlos Alberto em Novembro de 2005, no qual a Isabel participou como actriz. Enquanto registo informado e lúcido, comovente também, de uma experiência, este relato da sua - que, afinal de contas, também foi nossa - aventura como directora do Rivoli Teatro Municipal afirma-se doravante como um material indispensável para muitas outras histórias e reflexões que as curvas do futuro ainda nos permitam. 